\title{
Distinct Carbon Growth Mechanisms on the Components of Ni/YSZ Materials
}

\author{
Michaela Kogler ${ }^{1}$, Eva-Maria Köck ${ }^{1}$, Michael Stöger-Pollach ${ }^{2}$, Sabine Schwarz ${ }^{2}$, Thomas \\ Schachinger $^{2}$, Bernhard Klötzer ${ }^{1}$, Simon Penner ${ }^{1 *}$ \\ ${ }^{1}$ Institute of Physical Chemistry, University of Innsbruck, Innrain 80-82, A-6020 Innsbruck \\ ${ }^{2}$ University Service Centre for Transmission Electron Microscopy (USTEM), Vienna, \\ University of Technology, Wiedner Hauptstrasse 8-10/052, A-1040, Vienna, Austria
}

*Corresponding author: Fax: +43 512507 58198, Tel: +43 512507 58003, E-mail address: Simon.Penner@uibk.ac.at 


\begin{abstract}
Using pure YSZ and Ni-doped YSZ materials we provide a direct comparison of the morphology and specific growth mechanisms of carbon deposits following treatment in $\mathrm{CO}$ as the common component of reformate gas fuels at temperatures up to $1273 \mathrm{~K}$. Under these experimental conditions, carbon is deposited on both constituents following distinctly different pathways: metallic Ni particles are both encapsulated and subsequently act as catalysts for growth of carbon filaments - leading to chemically and electronically altered $\mathrm{Ni}$ particles. In contrast to that, also pure YSZ oxide particles are without exception only encapsulated by distorted graphitic layers of up to 2-3 individual layers. This carbon layer is not formed by carbon spillover from the Ni particle, but directly deposited on the oxide grains by $\mathrm{CO}$ dissociation. While the pathway over the metallic component is dominant at high $\mathrm{Ni}$ loadings, the oxide especially at lower loadings can contribute directly to the structural and chemical alterations of the electrode material by changing the physico-chemical properties, e.g. by altering the conductivity via $\mathrm{C}$-deposition at the intergrain regions or may also serve as additional carbon supply for re-distributed and dispersed "dusted" Ni particles attached to the carbon-covered YSZ grains.
\end{abstract}

Keywords: electron microscopy; oxides; nanostructures; electron-energy loss spectroscopy 


\section{Introduction}

Formation of carbon deposits especially on metallic substrates has been in the focus of research from both the fundamental scientific and technological viewpoint over the last decades [1]. Whereas the former is mainly aimed at a better understanding of the underlying structure and formation mechanisms, also triggered by chemical differences and differences to other carbon polymorphs [1], the latter basically reflects a two-sided sword [1-3]: although a number of applications have been reported and include e.g. their use in electronic devices, polymer additives, gas storage or as catalyst support material [1], in some research areas their formation and presence is considered detrimental [3-7].

A particular instructive example of the latter are solid-oxide fuel cells (SOFC's) [3]. Here, direct operation with carbon-containing fuels may lead to carbon deposition, and in extreme cases, carbon whisker formation on the anode part of the cell [3]. This might happen on the surface catalytically or by gas phase cracking at high operating temperatures of the SOFC's. As the anode material of choice still is in most cases a Ni cermet, this naturally happens mostly under participation of metallic Ni [3]. The latter, among others (such as Fe or Co), is a particular useful material for growth of carbon whiskers $[1,8-13]$. In the case of an SOFC, this might lead to short-circuiting the entire cell by dendritic growth through the electrode or by total rupture of the electrode material [3].

As for carbon whisker formation, almost all aspects of their properties and applications have been studied and also wrapped up in dedicated review articles [1]. However, having said that, up to date, in case of fuel cell operation, whisker formation is almost entirely discussed in connection with the behavior of the $\mathrm{Ni}$ constituent $[1,3,5,7-13]$. In that respect, particle size effects and supported/unsupported metal particles have been studied [14]. Putting this into perspective of SOFC research, $\mathrm{Ni}$ is usually present as cermet material with very high loadings (up to 50 weight $\%$ ) to provide sufficient conductivity through the electrode bulk [3]. As this is also a cost factor, strategies are necessary to reduce the Ni content but at the same 
time still keeping the conductivity and the catalytic performance. Systems with a lower Ni content are also important model systems for cermet materials which are treated by reformate gas, thereby creating finely dispersed $\mathrm{Ni}$ carbonyl species and, subsequently, $\mathrm{Ni}$ “dusting” [3]. This in turn artificially creates a system with dispersed Ni particles of different size. Recent studies indicate that this different Ni size distribution indeed affects the carbon deposition and growth: unsupported larger $\mathrm{Ni}$ particles do not show reactivity in either $\mathrm{CH}_{4}$ or $\mathrm{CO}$, but only in $\mathrm{C}_{2} \mathrm{H}_{4} / \mathrm{H}_{2}$, in contrast to $\mathrm{SiO}_{2}$-supported smaller ones [14]. Transferring this argumentation to Ni-YSZ systems, this implies that YSZ provides ionic conductivity, Ni acts as fuel catalyst and electronic conductor. Nevertheless, this appears to be only an incomplete picture: recent work suggests that carbon deposition under the chosen dedicated experimental conditions using carbon-containing fuels such as methane or ethylene might also occur on the oxide surfaces without metallic catalyst and might lead to layers of distorted graphite encapsulating the individual oxide particles or carbon-nanotube like features $[15,16]$. Using methane, this was shown to improve also the electronic conductivity of the electrode setup via enhancement of intra-grain and surface conductivity, finally leading to metallic conductivity at SOFC operating temperatures [15]. This in principle offers a convenient pathway of partially restoring the loss of electronic conductivity by decreasing the Ni content, but at the same time highlights the complex reaction network observed on realistic SOFC anode materials.

Apart from hydrocarbon fuels, also other carbon-containing molecules, such as CO can be used as precursors for carbon deposits [1]. This behavior is important insofar as methane is often transformed into syngas to avoid extensive coking [3], but raises the important question, if the obtained carbon deposits resemble the ones obtained in other fuels or show a different physico-chemical behavior, especially with respect to conductivity along eventually deposited carbon layers [15]. The data set on the effects of carbon-monoxide containing reaction mixtures on Ni/YSZ materials is overwhelming, but almost purely restricted to more complex mixtures such as syngas or even quaternary component mixtures [17-21]. The behavior in 
pure carbon monoxide has rarely been addressed, but both experimental [22] and theory work [23] indicate that carbon deposition following CO dissociation might be feasible on pure YSZ or the Ni-YSZ interface. The study in pure carbon monoxide is deemed especially important since the presence of different species (e.g. $\mathrm{H}_{2}, \mathrm{H}_{2} \mathrm{O}, \mathrm{CO}_{2}$ ) will impact the associated carbon formation $[21,24-26]$. This has been directly proven on Ni particles, where treatment in pure $\mathrm{CO}$ should lead to more closed forms of carbon, like shells or tubes, but $\mathrm{CO} / \mathrm{H}_{2}$ mixtures should yield open structures like filaments $[21,24,25]$. On oxides, these features have rarely been focussed upon. Naturally, the weighting of different growth modes (e.g. layer deposition, carbon nanotubes or whiskers) on YSZ in contact with differently sized Ni particles can be different under distinct experimental conditions, leading to altered behavior of the material under realistic operation conditions, e.g. of that of an SOFC. CO is known to be capable of creating finely dispersed $\mathrm{Ni}$ particles [3]: Ni carbonyl species are thus created via reaction with bulk Ni and possibly decompose on the YSZ surface. This indicates that also using CO, a very complex network of carbon chemistry is induced. The studies will also shed light on the general behavior of YSZ, which is one of the most widely used ionic conductors in SOFC research. The ion conduction is provided by doping the initial $\mathrm{ZrO}_{2}$ material with $\mathrm{Y}_{2} \mathrm{O}_{3}$ and thus creating oxygen vacancies, in parallel also stabilizing the tetragonal/cubic $\mathrm{ZrO}_{2}$ structure under ambient conditions. In addition, YSZ still remains mechanically stable at the required high operating temperatures of SOFCs [3].

We directly compare the growth mechanisms of carbon on pure YSZ and finely dispersed $\mathrm{Ni}$ particles on YSZ resulting from their reactivity towards $\mathrm{CO}$ and carbon deposition. This will help to understand if in the presence of finely dispersed Ni particles resulting from "dusting" or Ni-carbonyl mediated metal re-distribution in a finely dispersed form in a supported $\mathrm{Ni}$ /YSZ system similar effects as on a cermet materials will occur. This material will serve as a model system for Ni-dusted electrodes. Electron microscopy will be used to show that 
carbon deposition can take different routes on metallic and oxidic materials, both of them contributing to the behavior at high temperatures.

\section{Experimental}

Commercial YSZ powders and a self-prepared $\mathrm{Ni}(\mathrm{CO})_{4}$-treated Ni-YSZ sample exhibiting finely dispersed Ni particles on the YSZ surface were used as starting materials. Tetragonal YSZ (zirconium(IV)oxide yttria stabilized, nanopowder, containing 8 mol\% $\mathrm{Y}_{2} \mathrm{O}_{3}$ as stabilizer) was supplied by Sigma-Aldrich. To generate the Ni-YSZ sample, CO (1 mL s$\left.{ }^{-1}\right)$ was passed over Ni shot (Goodfellow $99.999 \%$ ) held at $373 \mathrm{~K}$ to form the $\mathrm{Ni}(\mathrm{CO})_{4}$ species. The latter was subsequently thermally decomposed over the YSZ sample at 473 - $523 \mathrm{~K}$.

Chemical and structural analysis was performed by employing electron microscopy. The transmission electron microscopic (TEM) investigations were performed by means of a FEI TECNAI F20 microscope, equipped with a field emission gun and a GATAN GIF Tridiem image filter. The energy resolution of the system is $0.8 \mathrm{eV}$. The TEM samples were prepared by means of focused ion beam (FIB) and gentle $\mathrm{Ar}^{+}$-ion polishing in order to remove beam damage from prior FIB milling. By crosschecking polished and non-polished samples, this behavior did not impact the carbon formation on the studied materials.

For SEM experiments, an SM 982 GEMINI ZEISS field emission scanning electron microscope was used. Prior to SEM imaging, the samples were coated with $10 \mathrm{~nm} \mathrm{Au/Pd}$ to improve its conductance.

X-ray diffraction experiments were performed ex-situ under ambient conditions using a Siemens D5000 Spectrometer and $\mathrm{Cu}-\mathrm{K}_{\alpha}$ radiation $(1.54178 \AA)$ at $300 \mathrm{~K}$ in the $2 \theta$ range 10 to $70^{\circ}$ with a step size of $0.02^{\circ}$.

The in situ impedance cell used for the experiments is composed of an outer quartz tube with two inner quartz tubes to which the sample and the electrodes are attached to. Heating is 
provided by a tubular Linn quartz furnace and controlled by a thermocouple (K-element), located in the reactor about $5 \mathrm{~mm}$ downstream of the sample, and a Micromega PID temperature controller. The impedance is measured by an IM6e impedance spectrometer (Zahner Messsysteme), which provides data on the frequency-dependent impedance and the phase angle of the current as a function of AC voltage excitation. The powder samples were pressed into pellets with a pressure of $2 \mathrm{t}(5 \mathrm{~mm}$ diameter, sample mass about $20 \mathrm{mg}$ ) and placed between two circular Pt electrodes which form a plate capacitor in mechanically enforced contact with the sample pellet. To record the impedance as a function of temperature, an excitation voltage of $20 \mathrm{mV}$ and a frequency of $1 \mathrm{~Hz}$ were used.

To induce the carbon deposition, the samples were treated in flowing dry CO (supplied by Messer, 4.7; flow $1 \mathrm{~mL} \mathrm{~s}^{-1}$ ) in a Linn quartz tube furnace at $1273 \mathrm{~K}$ for $1 \mathrm{~h}$ and finally recooled in flowing $\mathrm{CO}$ to $300 \mathrm{~K}$.

\section{Results and Discussion}

\subsection{Pure YSZ}

\section{Carbon deposition on pure YSZ}

Figure 1 shows a direct comparison of the structure and morphology of pure YSZ (Panel A) and Ni-YSZ (Panel B), obtained after a treatment in flowing CO $\left(1 \mathrm{~mL} \mathrm{~s}^{-1}\right)$ at $1273 \mathrm{~K}$. A more or less ordered microstructure with irregularly-shaped grains of about $50 \mathrm{~nm}$ size is seen on pure YSZ alongside pits and cracks in the surface. The Ni-YSZ sample shows a number of bright particles (50 - $100 \mathrm{~nm}$ in size) attached to the YSZ surface. Clustering of Ni particles is frequently observed (cf. encircled clusters in the inset). YSZ itself remains structurally and morphologically unaltered, except for the formation of a number of troughs and cracks especially in the region with the bright particles. The inset (marked by the red arrow) reveals that the bright particles act as catalytic nuclei for the formation of whisker-like features of 
about $50 \mathrm{~nm}$ width and several $\mu \mathrm{m}$ length. In Figures 6-9, these bright particles will be identified as chemically altered Ni particles. The whiskers will be shown to be composed of carbon, formed by $\mathrm{CO}$ disproportionation ( $2 \mathrm{CO} \leftrightarrows \mathrm{C}+\mathrm{CO}_{2}$, Boudouard reaction).

Figure 2 directly reveals the structure of deposited carbon on pure YSZ. Two nm-sized YSZ grains are visible, which are encapsulated by 2-5 layers of carbonaceous species. Carbon KEEL spectra collected directly at the end of the red arrow indicate that the layers basically consist of distorted nanocrystalline graphite [15].

To further highlight the extent of carbon deposition, energy-filtered TEM imaging has been performed on both pure YSZ and Ni-YSZ. Figure 3 shows these experiments for pure YSZ. In Panel A, the carbon K-edge intensity (blue) is superimposed on the total HAADF intensity (pink). Corroborating high-resolution TEM imaging, the carbon intensity is highest at the particle edges, clearly indicating encapsulation - as it is best seen in the inset carbon map. The particles at the bottom therefore show a particular enrichment of carbon at the particle edges. The latter is also seen by following the EELS line profile along the line shown in panel A. The HAADF intensity basically follows the particle outlines, whereas carbon shows a clear enrichment only at their edges.

\section{Mechanism of carbon deposition and its physico-chemical consequences on pure YSZ}

Mechanistic-wise, the first step of carbon deposition is always dissociation of the carboncontaining fuel [1] - in the present case, CO. On oxide surfaces, this first step is controversly discussed. On pure $\mathrm{ZrO}_{2}$ results indicate a potential catalytic influence of $\mathrm{Zr}$ oxygen-deficient substoichiometric defect centers on carbon deposition following treatment in ethylene [16], but contradicting evidence is presented for carbon deposition on $\mathrm{AlO}_{\mathrm{x}}$ samples as a consequence of treatment in acetylene [27,28]. Catalyst-assisted transformation of hydrocarbons into various carbon nanoarchitectures (e.g. nanotubes, graphene or graphitic materials) over non-metallic templates (e.g. oxides or carbides) is also reported 
$[1,8,15,16,29]$. The role of surface chemistry (e.g. hydroxylation degree of the surface) is thereby significant [15]. Especially at high temperatures, fuel conversion via gas phase radical chemistry is more important and well established, e.g. for methane [15,30,31]. The role of the catalytic oxide surface is to steer the individual gas phase intermediates via direct interaction to the product of choice. Using methane, this mechanism has been proposed and verified on a number of oxides, including $\mathrm{Y}_{2} \mathrm{O}_{3}, \mathrm{ZrO}_{2}$ and $\mathrm{YSZ}[15,16,30]$.

Involving $\mathrm{CO}$ as fuel, a different mechanism of carbon deposition is more plausible: carbon can be formed from $\mathrm{CO}$ via the Boudouard equilibrium $2 \mathrm{CO} \leftrightarrows \mathrm{CO}_{2}+C$ [9,32]. At the high operating temperatures of an SOFC, the equilibrium in principle lies almost $100 \%$ on the CO side [33]. However, as the materials are treated under flowing conditions, $\mathrm{CO}_{2}$ is permanently removed from the reaction mixture and the equilibrium thus forced towards $\mathrm{CO}_{2}$ and $\mathrm{C}$. Carbon formation via the Boudouard reaction on metals is a well-documented phenomenon and involves a sequence of elementary reaction steps including dissociative adsorption of CO, carbon formation, reaction of adsorbed oxygen atoms with co-adsorbed $\mathrm{CO}$ to form $\mathrm{CO}_{2}$ and subsequent C-diffusion and segregation phenomena [9]. The Boudouard equilibrium is also one of the key reactions occurring in a blast furnace of iron ore reduction. Hence, the reduction of $\mathrm{Fe}_{2} \mathrm{O}_{3}$ in $\mathrm{CO}$ atmosphere also involves the Boudouard reaction, leading to dynamic $\mathrm{CO}$ formation (from carbon and $\mathrm{CO}_{2}$ ) and disproportionation, but also carburization [33]. In fact, metallic iron, graphite and also iron-carbide species have been identified by Xray diffraction [32]. However, the XR diffractogram of YSZ before and after the treatment are almost indistinguishable, except for a somewhat larger background in the black diffractogram (Figure 4). Neither crystalline graphitic carbon, substantial amounts of amorphous carbon, nor any carbide species are present. Consequently, we also exclude a substantial degree of reduction of bulk YSZ by CO during the treatment.

In turn, the Boudouard equilibrium, following CO adsorption, takes a different route on YSZ without participation of metallic species, but still involving $\mathrm{CO}$ bond scission. Previous 
experiments showed that YSZ in contact with reducing agents (e.g. $\left.\mathrm{H}_{2}\right)$ is slightly reducible on the surface or in surface-near regions, but bulk reduction yielding metallic species or a large number of bulk vacancies is excluded [34]. In analogy, CO might e.g. dissociate on coordinatively unsatured sites by refilling of vacancies and at the same time, forming metalcarbon bonds (i.e. carbidization occurs). Whether this is e.g. visible as a compound in XRD patterns is then a matter of extent of carbon deposition or crystallization behavior.

In summary, this mechanism resembles a Mars-van-Krevelen pathway which has been already observed for reduced $\mathrm{TiO}_{\mathrm{x}}$ samples exhibiting $\mathrm{Ti}^{3+}$ cations [35-37]. The further fate of the carbon species is subsequently strongly dependent of the segregation and diffusion behavior of carbon in the bulk. On metallic samples, segregation has been shown to lead to whisker and nanotube formation, but such carbon architectures have never been observed on YSZ following carbon deposition from CO. In conclusion, the activation barrier of carbon diffusion in bulk YSZ must be sigificantly higher, thus leading to layered structures encapsulating the particles.

This layered structure, as already shown for similar experiments using methane as carbon precursor $[15,16]$, significantly influences the physico-chemical properties of the electrode material. Of special importance in e.g. SOFC-related research is the increase in conductivity along the graphite-covered YSZ grains. Using methane, even metallic conductivity could be reached at comparable temperatures [15]. In CO, on the contrary, the conductivity could not be increased to a comparably high (metallic) value (Figure 5). Although it increases 5-6 orders of magnitude, the value for bulk anion conductivity of the YSZ powder pellet in inert gas atmosphere is hardly reached in $\mathrm{CO}$, despite the $2-3 \mathrm{~nm}$ thick carbon layer present on the grain surfaces (as shown in Figure 3). The grain-covering carbon layer does therefore hardly contribute to the total conductivity of the sample. Hence, although the structure of the carbon layers resulting from treatment in either methane or $\mathrm{CO}$ is very similar, their properties appear to be at least qualitatively different to some extent. A possible explanation for the lower 
conductivity in the case of $\mathrm{CO}$ might be associated with a lower overall amount of deposited carbon, leading to more isolated, less percolated carbon islands with a diminished conductivity.

\subsection{Ni onYSZ}

\section{Carbon deposition on Ni-YSZ}

Figure 6 highlights an overview TEM image with YSZ grains, a Ni particle and the onset of a carbon whisker (seen as sphere because the whisker is cut perpendicular to its axis). That indeed the wire-like features are composed of carbon is derived from the associated EEL map shown in the lower right image. Structurally, the whiskers are related to distorted graphite, as the corresponding high-resolution TEM image (Figure 7, region marked by red square in Figure 6) shows mostly amorphous carbon with poorly crystallized regions of graphite.

The presence of graphitic carbon is also reflected in the EEL spectra taken at various spots of the carbon whisker (indicated by indices " 1 " and " 2 ") showing the typical C-K edge shape (Figure 8, Panel B and C). The spatial distribution of YSZ, Ni and carbon is again shown in the energy-filtered TEM image of Panel A as a superposition of the Ni-L (green), Y-L (blue) and C-K (red) edge intensities. Due to the low overall carbon intensity around the YSZ grains in comparison to that around the Ni particles, the carbon layer highlighted in Figure 2 is hardly visible. In contrast, encapsulation of $\mathrm{Ni}$ particles by carbon and subsequent whisker growth is clearly visible.

As the energy-filtered image in Figure 8 A especially for the larger Ni particle in the upper right corner indicates some carbon interdiffusion into the Ni particle and in order to exclude the possibility of a simple carbon overlayer essentially encapsulating $\mathrm{Ni}$, additional chemical and structural analysis of these particles has been conducted (Figure 9). This analysis is based on a principal component analysis in combination with a chemical concentration analysis: starting from a HAADF image of this Ni particle (upper left corner), showing internal contrast 
possibly arising from chemical differences within the Ni particle, chemical concentration analysis reveals the $\mathrm{Ni}$ and $\mathrm{C}$ distribution: $\mathrm{Ni}$ is found mainly in the triangle-shaped center of the particle (deduced from the bright $\mathrm{Ni}$ intensity in the $\mathrm{Ni}$ and the $\mathrm{Ni} / \mathrm{C}$ ratio concentration map), carbon mainly at the particle edges. This of course, does not tell anything about possible chemical differences of e.g. Ni, induced by carbon deposition and growth. To unravel these differences, a principal component analysis has been carried out. For this purpose, EEL spectra of two principal Ni components (C1-red, C2-green), shown in the lower middle panel have been collected. The spatial distribution of these two components within the Ni particle is plotted in the map and shown in the lower right corner. According to the red EEL spectrum, the $\mathrm{C} 1$ component is metallic $\mathrm{Ni}$. This is deduced from the associated intensity ratio of the $\mathrm{L}_{3} / \mathrm{L}_{2}$ peaks. According to refs. [38, 39], in the case of metallic $\mathrm{Ni}$, the intensity ratio of $\mathrm{L}_{3}$ (at $\sim 855 \mathrm{eV}$ ) to $\mathrm{L}_{2}($ at $\sim 870 \mathrm{eV}$ ) are close to $1.5-1.8$, whereas for $\mathrm{NiO}$, this ratio subsequently increases to 2.2-2.5. In the present case, the determined $\mathrm{L}_{3} / \mathrm{L}_{2}$ peak ratio is about 1.5 , clearly indicating the presence of metallic Ni. The EEL spectrum of the $\mathrm{C} 2$ component exhibits peaks of similar intensity, but a significantly higher intensity between the two peaks (about 20\% difference). As there is only $\mathrm{Ni}$ and carbon present within the particle, we can exclude (oxidized) Ni species of higher valence states. This is also corroborated by the similar overall shape of both EEL spectra. Hence, the second Ni component can therefore be directly linked to the carbon content within the particle, since a simple carbon overlayer on or beneath the surface would not lead to a chemical difference in the Ni species and would therefore not cause an associated change in the EEL spectrum. Possible explanations are discussed in the following section.

\section{Mechanism of carbon deposition and its physico-chemical consequences on Ni-YSZ}

Carbon formation following adsorption and dissociation of carbon-containing fuels followed by dissolution and re-segregation of the so-formed $\mathrm{C}$ atoms in various transition metals, but especially in $\mathrm{Ni}$, is an extremely well-documented phenomenon $[1,7,10]$. $\mathrm{Ni}$ is also a well- 
appreciated catalyst for the growth of more complex carbon architectures, including nanotubes and whiskers [1]. For the latter, at least three different growth modes, including a vapor-liquid-solid, a vapor-solid-solid and a carbide-assisted growth are discussed [8].

The most important component in the latter mechanism is the $\mathrm{Ni}_{3} \mathrm{C}$ phase: its influence is so far discussed ambivalently - while it is clear that the mechanism involves bulk $\mathrm{Ni}_{3} \mathrm{C}$ as an intermediate phase, it is reported that metastable $\mathrm{Ni}_{3} \mathrm{C}$ decomposes into $\mathrm{Ni}$ and graphitic carbon [1]. This process is also expected from the available phase diagrams of the Ni-C system, which include the metastable bulk $\mathrm{Ni}_{3} \mathrm{C}$ phase [40]. Growth then occurs on metallic $\mathrm{Ni}$ and no whiskers are present as long as $\mathrm{Ni}_{3} \mathrm{C}$ is stable. On the contrary, very recent results by $\mathrm{Yu}$ et al. indicate that carbon can be also precipitated from (001) planes of faceted $\mathrm{Ni}_{3} \mathrm{C}$ nanoparticles, that is, coexistence of whiskers and $\mathrm{Ni}_{3} \mathrm{C}$ is reported [8,41]. Hence, the role of $\mathrm{Ni}_{3} \mathrm{C}$ is still far from clear. However, despite the obvious deficiencies in knowledge, surface or bulk Ni-carbide phases represent the link between carbon formation/dissolution and graphite/graphene/whisker growth on various systems. On well-defined single crystals or foils, $\mathrm{Ni}_{2} \mathrm{C}$ or other surface carbide phases are the intermediate phase for subsequent carbon growth in the temperature region below $773 \mathrm{~K}[42,43]$. In the present case, detailed electron microscopy analysis did not show substantial signs of a $\mathrm{Ni}_{3} \mathrm{C}$ phase and we assume that the chemically altered Ni species ("C2") represents a rather high amount of carbon dissolved into the $\mathrm{Ni}$ bulk, but without long-range ordering toward a crystallographically well-defined carbide phase. This coincides with stability determinations of the $\mathrm{Ni}_{3} \mathrm{C}$ phase [41], indicating decomposition into $\mathrm{Ni}$ and $\mathrm{C}$ at $873 \mathrm{~K}$. Note also that under the chosen experimental conditions, only so called "extrusion filaments" are observed, without a Ni catalyst particle operating at the front of the growing whisker [44,45]. This indicates a process controlled by surface diffusion, as suggested by Baker et al. [46].

The implications of these observations are therefore directly related to the consequences of "Ni dusting", a phenomenon occurring subsequent to thermal decomposition of volatile $\mathrm{Ni}$ 
carbonyl species, leading to finely dispersed Ni particles. The reconstructed Ni particles might act as catalyst for whisker formation, with all structural consequences of electrode failure, and indirectly, might lead to loss of structural integrity of the YSZ material. Hence, the route of avoiding carbon fuels (leading to pronounced coking) by converting them into syngas (i.e. CO and $\mathrm{H}_{2}$ ) does not necessarily suppress coke formation substantially.

As for the stability of the obtained carbon nanostructures, it is well known that it is very much dependent on the post-treatment and the removal of the carbon-containing reaction gas [25]. On Ni particles, intermediarily formed graphite layers have been suspected to be severly altered by carbon precipitation from supersaturated Ni particles after removing the reaction gas. Consequently, the carbon structures obtained after re-cooling in $\mathrm{CO}$ are those which are stable enough to survive the transfer to air.

\section{Conclusions}

As a concluding remark, our results indicate the co-existence of distinct carbon morphologies on $\mathrm{Ni}$ and YSZ, as proven on Ni-YSZ systems at high reaction temperatures. In a bullet-bybullet comparative discussion of pure YSZ and Ni-YSZ, the following conclusions can be drawn:

- Ni-carbonyl-mediated Ni re-distribution leads to small particles, acting as nuclei for carbon whisker growth. Whisker growth exclusively occurs via formation of so-called “extrusion" mechanisms in pure $\mathrm{CO}$, starting from $\mathrm{C}$-rich (but not crystalline $\mathrm{Ni}_{3} \mathrm{C}$ ) regions within the particles.

- On YSZ surfaces, 2-3 nm thick disordered graphitic layers, but no carbon whiskers or nanotube-like features, are observed under the same conditions. This layer in turn does hardly affect the conductivity properties of YSZ, but acts as an additional source of carbon supply for the Ni particles attached to the graphite-covered YSZ grains. 
- In the context of SOFC-related research, in contrast to the general view on the carbon-induced deactivation mechanisms in metal-oxide systems, which essentially ascribes the deactivation entirely to metallic $\mathrm{Ni}$, the situation rather involves a dynamic carbon reaction and deposition network involving both metallic and oxidic component, also and especially if pure $\mathrm{CO}$ is used as carbon precursor.

- The pathway of carbon deposition and growth is different on both components: encapsulation and subsequent carbon whisker growth mainly occurs on the metallic part, but only encapsulation is observed on the oxide. Nevertheless, although especially in the case of $\mathrm{Ni}$ cermet materials with very high $\mathrm{Ni}$ loadings whisker formation is certainly predominant, the influence of the oxide might be considerable especially for lower loadings.

\section{Acknowledgments}

We thank the FWF (Austrian Science Foundation) for financial support under the project F4503-N16. K. Pfaller and D. Schmidmair are greatly acknowledged for assistance with SEM imaging and X-ray diffraction measurements.

\section{References}

[1] K.de Jong, J. W. Geus, Carbon Nanofibers: Catalytic Synthesis and Applications, Catal. Rev.-Sci. Eng. 42 (2000) 481-510 and references therein 
[2] J. R. Nielsen-Rostrup, Sulfur-Passivated Nickel Catalysts For Carbon-Free Steam Reforming of Methane, J. Catal. 85 (1984) 31-40 and references therein

[3] S.McIntosh, R. J. Gorte, Direct Hydrocarbon Solid Oxide Fuel Cells, Chem. Rev. 104 (2004) 4845-4865

[4] D. Duprez, M. C. Demicheli, P. Marecot, J. Barbier, O. A. Ferretti, E. N. Ponzi, Deactivation of Steam Reforming Model Catalysts by Coke Formation, J. Catal. 124 (1990) 324-335

[5] J. B. Claridge, M. L. H. Green, S. C. Tsang, A. P. E. York, A. T. Ashcroft, P. D. Battle, A Study of Carbon Deposition on Catalysts During the Partial Oxidation of Methane to Synthesis Gas, Catal. Lett. 22 (1993) 299-305

[6] A. Lanzini, P. Leone, C. Guerra, F. Smeacetto, N. P. Brandon, M. Santarelli, Durability of Anode Supported Solid Oxide Fuel Cells (SOFC) Under Direct Dry-Reforming of Methane, Chem. Eng. J. 220 (2013) 254-263

[7] D. L. Trimm, Catalyst Design for Reduced Coking, Appl. Catal. 5 (1983) 263-290

[8] B. Yu, S. Wang, Q. Zhang, Y. He, H. Huang, J. Zou, Ni ${ }_{3}$ C-Assisted Growth of Carbon Nanofibers at $300^{\circ} \mathrm{C}$ by Thermal CVD, Nanotechnology 25 (2014) 325602-1 - 325602-7.

[9] J. W. Snoeck, G. F. Froment, M. Fowles, Steam $/ \mathrm{CO}_{2}$ Reforming of Methane. Carbon Filament Formation by the Boudouard Reaction and Gasification by $\mathrm{CO}_{2}$, by $\mathrm{H}_{2}$ and by Steam: Kinetic Study, Ind. Eng. Chem. Res. 41 (2002) 4252-4265

[10] A. J. H. M. Kock, P. K. de Bokx, E. Boellard, W. Klop, J. W. Geus, The Formation of Filamentous Carbon on Iron and Nickel Catalysts, J. Catal. 96 (1985) 468-480

[11] I. Alstrup, A New Model Explaining Carbon Filament Growth on Nickel, Iron and Ni-Cu Alloy Catalysts, J. Catal. 109 (1988) 241-251

[12] J. R. Nielsen-Rostrup, D. L. Trimm, Mechanisms of Carbon Formation on NickelContaining Catalysts, J. Catal. 48 (1977) 155-165 
[13] R. T. K. Baker, M. A. Barber, P. S. Harris, F. S. Feates, R. J. Waite, Nucleation and Growth of Carbon Deposits from the Nickel Catalyzed Decomposition of Acetylene, J. Catal. 26 (1972) 51-62

[14] M. L. Toebes, J. H. Bitter, A. J. van Dillen, K. P. de Jong, Impact of the Structure and Reactivity of Nickel Particles on the Catalytic Growth of Carbon Nanofibers, Catal. Today 76 (2002) 33-42

[15] M. Kogler, E. M. Köck, L. Perfler, T. Bielz, M. Stöger-Pollach, W. Hetaba, M. Willinger, X. Huang, M. Schuster, B. Klötzer, S. Penner, Methane Decomposition and Growth on $\mathrm{Y}_{2} \mathrm{O}_{3}$, Yttria-Stabilized Zirconia, and $\mathrm{ZrO}_{2}$, Chem. Mater. 26 (2014) 1690-1701

[16] S. A. Steiner III, T. F. Baumann, B. C. Bayer, R. Blume, M. A. Worsley, W. J. MoberlyChen, E. L. Shaw, R. Schlögl, A. Hart, S. Hofmann, B. L. Wardle, Nanoscale Zirconia as a Nonmetallic Catalyst for Graphitization of Carbon and Growth of Single- and Multiwall Carbon Nanotubes, J. Am. Chem. Soc. 131 (2009) 12144-12154

[17] M. Lebreton, B. Delanoue, E. Baron, F. Ricoul, A. Kerihuel, A. Subrenat, O. Joubert, A. Le Gal La Salle, Effects of Carbon Monoxide, Carbon Dioxide, and Methane on Nickel/Yttria-Stabilized Zirconia-Based Solid Oxide Fuel Cells Performance for Direct Coupling With a Gasifier, Int. J. Hydr. Energ. 40 (2015) 10231-10241

[18] X. Ye, S. Wang, J. Zhou, F. Zeng, H. Nie, T. Wen, Assessment of the Performance of Ni-Yttria-Stabilized Zirconia Anodes in Anode-Supported Solid Oxide Fuel Cells Operating on $\mathrm{H}_{2}$-CO Syngas Fuels, J. Power Sources 195 (2010) 7264-7267

[19] V. Alzate-Restrepo, J. M. Hill, Carbon Deposition on Ni/YSZ Anodes Exposed to CO/H 2 Feeds, J. Power Sources 195 (2010) 1344-1351

[20] C. M. Chun, J. D. Mumford, T. A. Ramanarayanan, Carbon-Induced Corrosion of Nickel Anode, J. Electrochem. Soc. 147 (2000) 3680-3686

[21] P. E. Nolan, M. J. Schabel, D. C. Lynch, A. H. Cutler, Hydrogen Control of Carbon Deposit Morphology, Carbon 33 (1995) 79-85 
[22] Y. Hirata, A. Masahiro, N. Matsanuaga, Electrochemical Decomposition of $\mathrm{CO}_{2}$ and $\mathrm{CO}$ Gases Using Porous Yttria-Stabilized Zirconia Cell, Ceram. Int. 38 (2012) 6377-6387

[23] Y. Zhang, Z. Yang, M. Wang, Understanding On the Carbon Deposition on the Nickel/Yttrium-Stabilized Zirconia Anode Caused by the CO Containing Fuels, J. Power Sources 279 (2015) 759-765

[24] P. E. Nolan, D. C. Lynch, A. H. Cutler, Catalytic Disproportionation of CO in the Absence of Hydrogen: Encapsulating Shell Carbon Formation, Carbon 32 (1994) 477-483

[25] P. E. Nolan, D. C. Lynch, A. H. Cutler, Graphite Encapsulation of Catalytic Metal Nanoparticles, Carbon 34 (1996) 817-819

[26] V. Subotic, C. Schluckner, C. Hochenauer, Solid Oxide Fuel Cells: A Promising Future Technology, TU Graz Research Journal, 12 (2014) 27-29

[27] S. Noda, K. Hasegawa, H. Sugime, K. Kakehi, Z. Zhang, S. Maruyama, Y. Yamaguchi, Millimeter-Thick Single-Walled Carbon Nanotube Forests: Hidden Role of Catalyst Support, Jpn. J. Appl. Phys. Part 246 (2007) L399-L401

[28] C. Mattevi, S. Hofmann, M. Cantoro, A. C. Ferrari, J. Robertson, C. Castellarin-Cudia, S. Dolafi, A. Goldoni, C. Cepek, Surface-Bound Chemical Vapour Deposition of Carbon Nanotubes: In-Situ Study of Catalyst Activation, Phys. E 40 (2008) 2238-2242

[29] H. Yoshida, T. Shimizu, T. Uchiyama, H. Kohno, Y. Homma, S. Takeda, Atomic-Scale In-Situ Observation of Carbon Nanotube Growth From Solid State Iron Carbide Nanoparticles, Nano Lett. 8 (2008) 2082-2086.

[30] U. Zavyalova, M. Holena, R. Schlögl, M. Baerns, Statistical Analysis of Past Catalytic Data on Oxidative Methane Coupling for New Insights into the Composition of HighPerformance Catalysts, ChemCatChem 3 (2011) 1935-1947

[31] C.J. Chen, M. H. Back, R. A. Back, The Thermal Decomposition of Methane. I. Kinetics of the Primary Decomposition to $\mathrm{C}_{2} \mathrm{H}_{6}+\mathrm{H}_{2}$; Rate Constant for the Homogeneous 
Unimolecular Dissociation of Methane and its Pressure Dependence, Can. J. Chem. 53 (1975) $3580-3590$

[32] K. Mondal, H. Lorethova, E. Hippo, T. Wiltowski, S. B. Lalvani, Reduction of Iron Oxide in Carbon Monoxide Atmosphere - Reaction Controlled Kinetics, Fuel Pross. Technol. 86 (2004) 33-47

[33] R. D. Lide, CRC Handbook of Chemistry and Physics. 90. Edition. Taylor \& Francis, 2009

[34] M. Kogler, E. M. Köck, T. Bielz, K. Pfaller, B. Klötzer, D. Schmidmair, L. Perfler, S. Penner, Hydrogen Surface Reactions and Adsorption Studied on $\mathrm{Y}_{2} \mathrm{O}_{3}$, YSZ and $\mathrm{ZrO}_{2}, \mathrm{~J}$. Phys. Chem. C 118 (2014) 8435-8444

[35] A. M. Menetrey, C. Markovits, Reactivity of a Reduced Metal Oxide Surface: Hydrogen, Water and Carbon Monoxide Adsorption on Oxygen Defective Rutile $\mathrm{TiO}_{2}$ (110), Surf. Sci. $524(2003) 49-62$

[36] M. A. Vannice, C. Sudhakar, A Model for the Metal-Support Effect Enhancing Carbon Monoxide Hydrogenation Rates Over Platinum-Titania Catalysts, J. Phys. Chem. 88 (1984) $2429-2437$

[37] G. B. Raupp, J. A. Dumesic, Adsorption of Carbon Monoxide, Carbon Dioxide, Hydrogen, and Water on Titania Surfaces With Different Oxidation States, J. Phys. Chem. 89 (1985) 5240-5249

[38] C. C. Ahn, O. Krivanek, EELS Atlas, Gatan @, 1983

[39] R. Thalinger, M. Heggen, D. Stroppa, M. Stöger-Pollach, B. Klötzer, S. Penner, Formation and Stability of Small Well-Defined $\mathrm{Cu}-$ and Ni Oxide Particles, Mater. Chem. Phys. 143 (2013) 184-194.

[40] M. Singleton, R.Nash, The C-Ni (Carbon-Nickel) System, Bulletin of Alloy Phase Diagrams 10 (1989) 121-126 
[41] C. Ducati, I. Alexandrou, M. Chhowalla, J. Robertson, G. A. Amaratunga, The Role of the Catalytic Particle in the Growth of Carbon Nanotubes by Plasma Enhanced Chemical Vapor Deposition, J. Appl. Phys. 95 (2004) 6387-6401

[42] P. Jacobson, B. Stöger, A. Garhofer, G. S. Parkinson, M. Schmid, R. Caudillo, U. Diebold, Nickel Carbide as a Source of Grain Rotation in Epitaxial Graphene, ACS Nano 6 (2012) 3564-3572.

[43] J. Lahiri, T. Miller, L. Adamska, I. I. Oleynik, M. Batzill, Graphene Growth on Ni (111) by Transformation of a Surface Carbide, Nano Lett. 11 (2010) 518-522

[44] S. B. Sinnott, R. Andrews, D. Qian, A. M. Rao, Z. Mao, E. C. Dickey, F. Derbyshire, Model of Carbon Nanotube Growth Through Chemical Vapor Deposition, Chem. Phys. Lett. 355 (1999) 25-30

[45] R. T. K. Baker, R. J. Waite, Formation of Carbonaceous Deposits From the PlatinumIron Catalyzed Decomposition of Acetylene, J. Catal. 37 (1975) 101-105

[46] R. T. K. Baker, P. S. Waite, The Formation of Filamentous Carbon, in Chemistry and Physics of Carbon (P.L. Walker Jr, P. A.Thrower, Eds.), 14, Marcel Dekker, New York, 1978, p.83

\section{Figures}



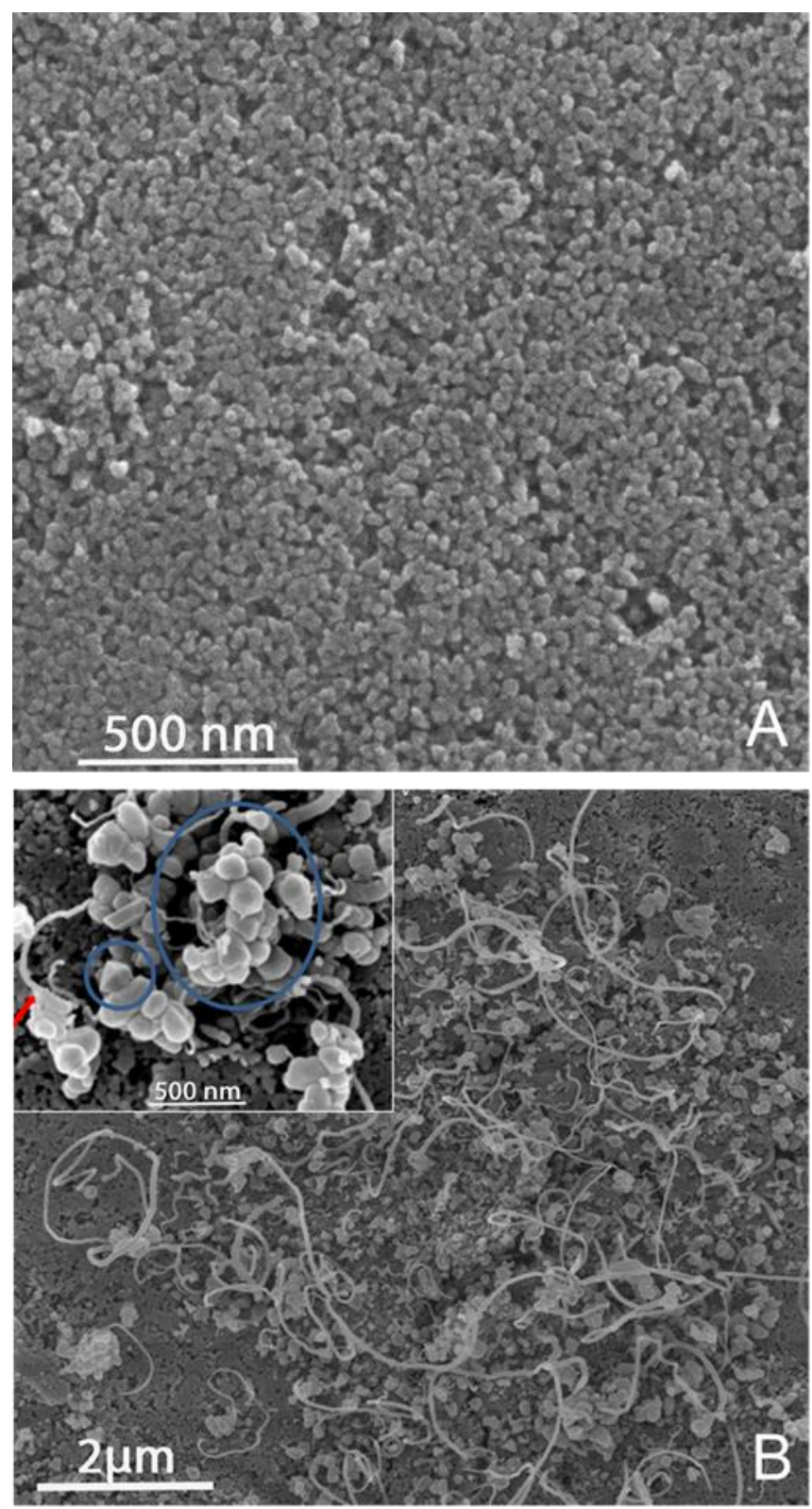

Figure 1: Scanning electron microscopic images of pure YSZ (panel A) and Ni/YSZ (panel B) after a treatment in flowing $\mathrm{CO}\left(1 \mathrm{mLs}^{-1}\right)$ at $1273 \mathrm{~K}$ for $1 \mathrm{~h}$. The inset in panel B shows a close-up view of a region with accumulated Ni particles serving as catalyst for carbon whisker growth. The red arrow denotes the interfacial region of Ni particle and carbon whisker, the blue circles well-facetted Ni particles. 


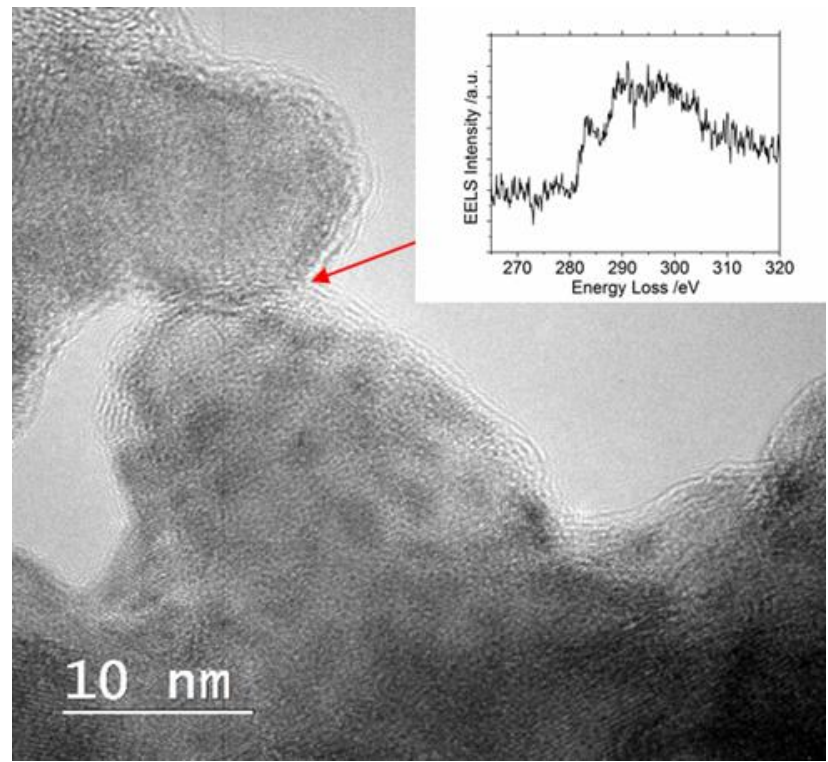

Figure 2: Transmission electron micrograph of YSZ grains after a treatment in flowing CO (1 $\mathrm{mLs}^{-1}$ ) at $1273 \mathrm{~K}$. The encapsulating carbon layer is clearly visible and identified as distorted graphitic by the EEL spectrum shown as inset and taken at the at the end of the red arrow. 

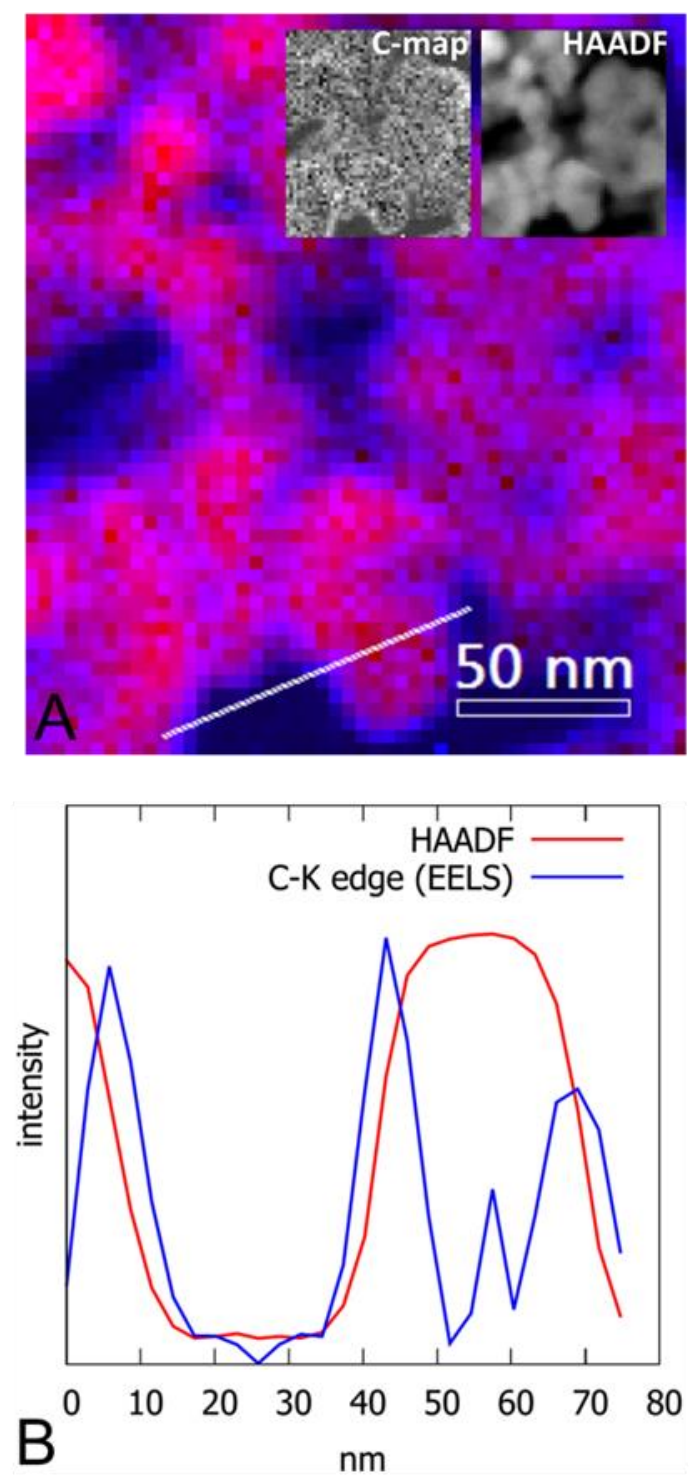

Figure 3: Panel A: Energy-filtered TEM image of pure YSZ with the carbon K-edge intensity (blue) superimposed on the total HAADF intensity (pink). The separated maps are shown in the upper right corner. Panel B: EELS line profile of the total HAADF intensity (red) and carbon K-edge (blue) intensity measured along the white line in panel A. 


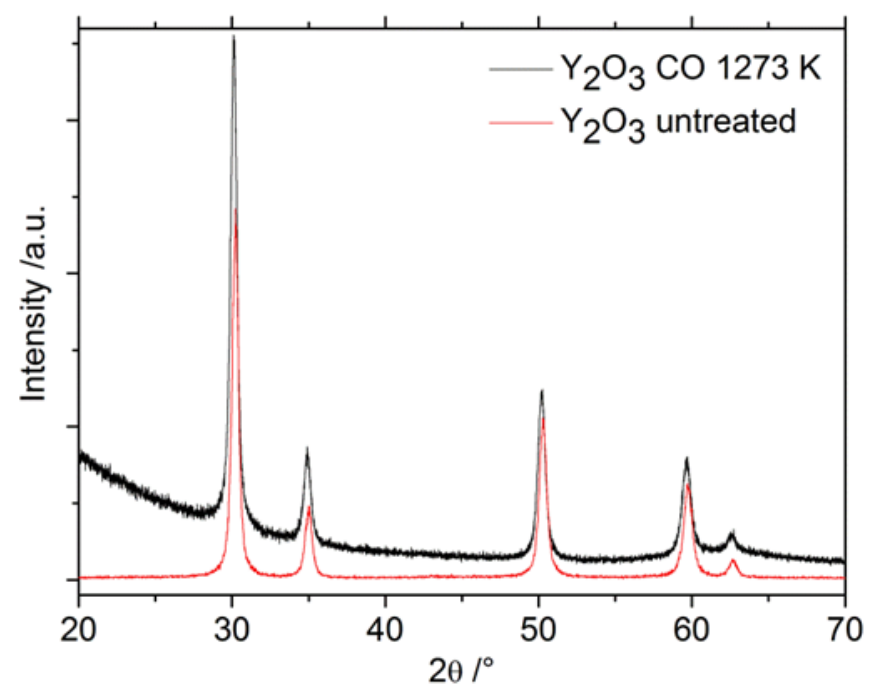

Figure 4: XRD diffractograms of untreated YSZ (red) and YSZ (black) after exposure to flowing $\mathrm{CO}\left(1 \mathrm{~mL} \mathrm{~s}^{-1}\right)$ at $1273 \mathrm{~K}$. 


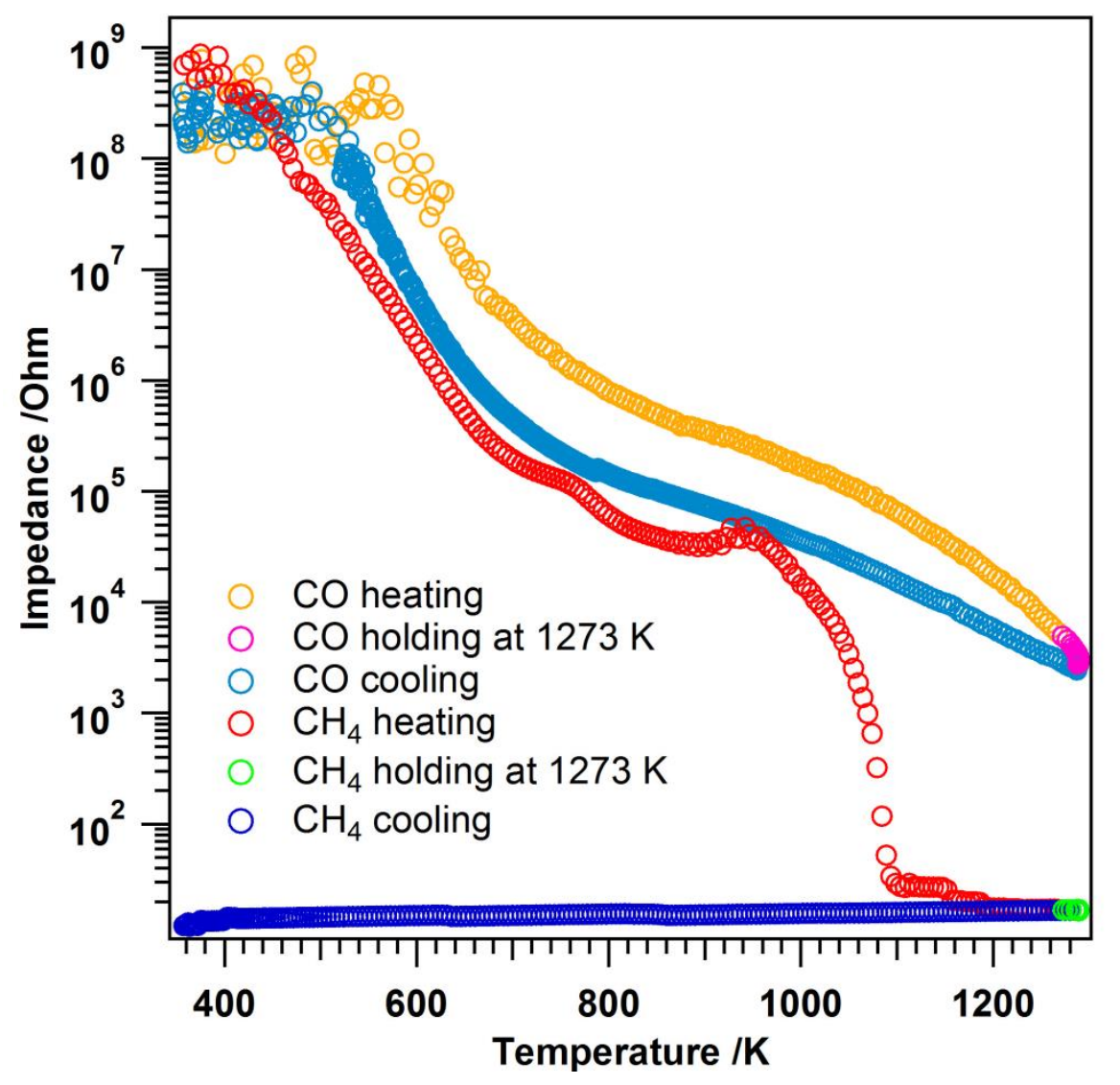

Figure 5: Electric conductivity during a heating-cooling cycle of pure YSZ followed in situ during exposure to flowing $\mathrm{CO}$ in comparison to methane (both $1 \mathrm{~mL} \mathrm{~s}^{-1}$ ) between $360 \mathrm{~K}$ and $1273 \mathrm{~K}$. 


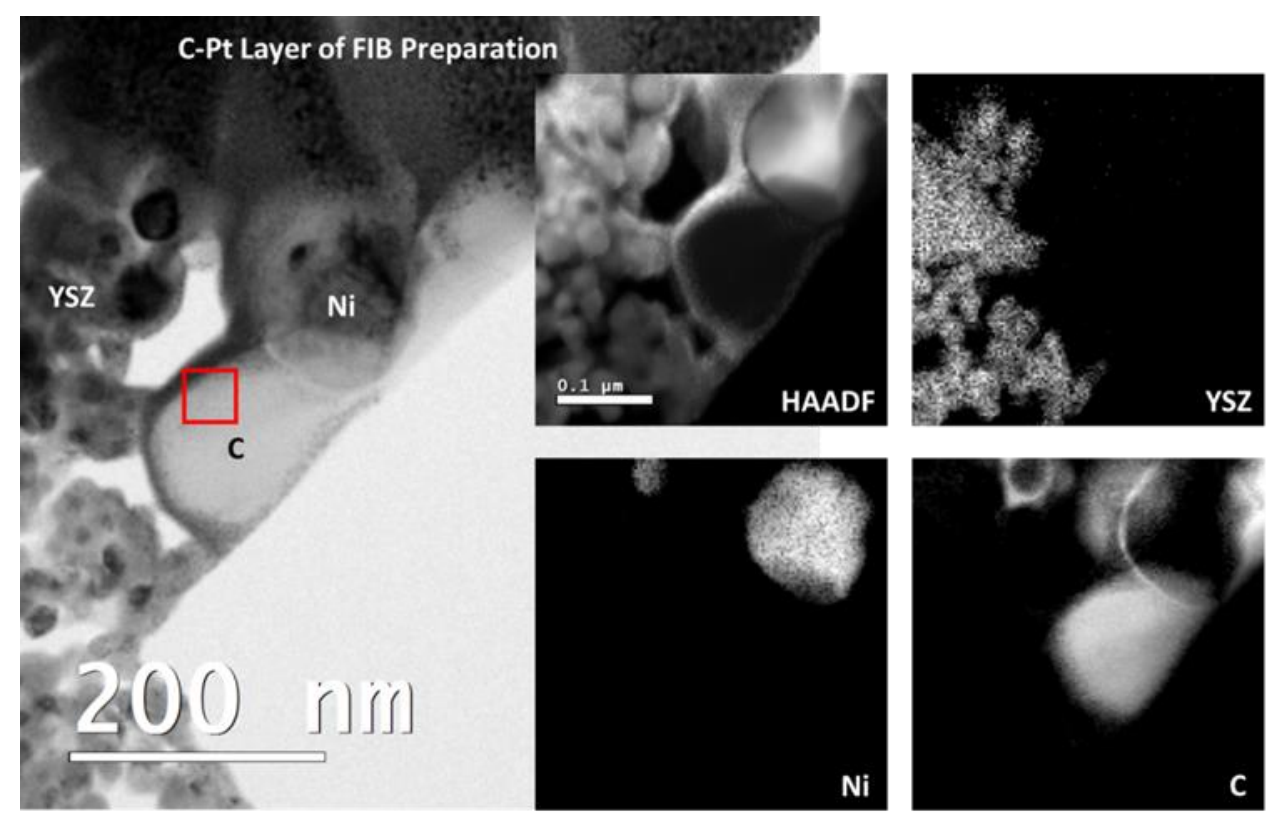

Figure 6: Bright field TEM image of a FIB-prepared layer of a Ni/YSZ powder (shown in Figure 1B) after exposure to flowing CO $\left(1 \mathrm{mLs}^{-1}\right)$ at $1273 \mathrm{~K}$ for $1 \mathrm{~h}$. Representative Ni and YSZ particles, as well as the front facet of a carbon whisker have been marked. The four small images on the right highlight the total HAADF intensity, as well as the individual intensities of the C-K edge, the Y-L edge and the Ni-L edge. The red square indicates the carbon region, which has been used for high-resolution imaging (cf. Figure 7). 


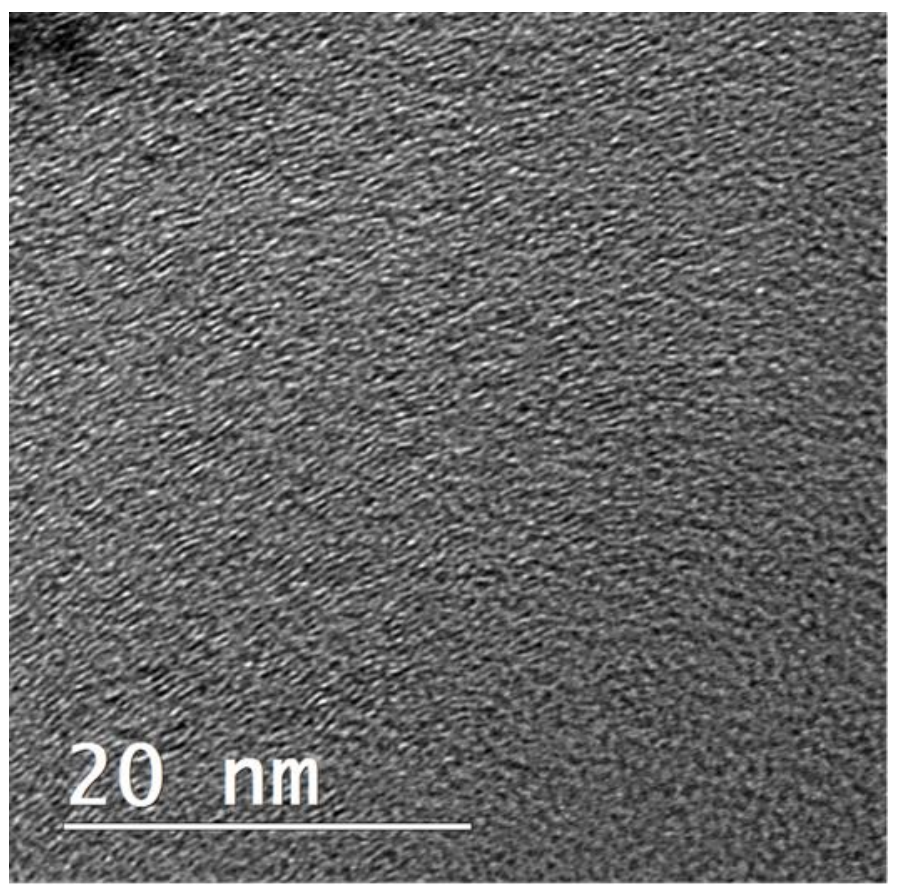

Figure 7: High-resolution TEM image of the red-squared carbon region of Figure 6 with distorted crystalline graphite regions. 

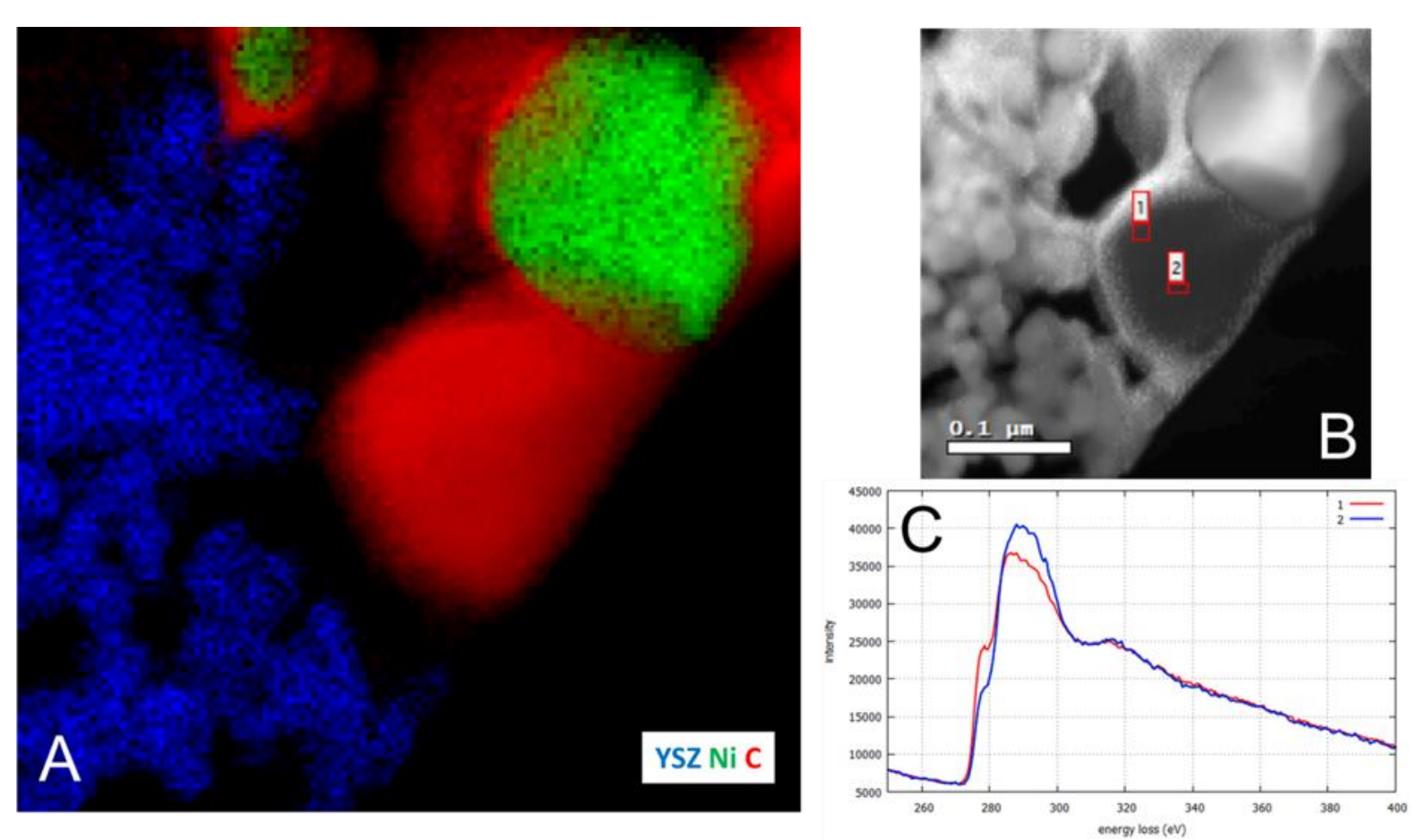

Figure 8: Energy-filtered TEM image of Ni/YSZ with C-K edge (red), Y-L edge (blue) and Ni-L edge (green) (Panel A). HAADF image of the same region (panel B) and EEL C-K spectra of two representative regions (denoted 1 (red) and 2 (blue) in panel B) shown in panel C. 


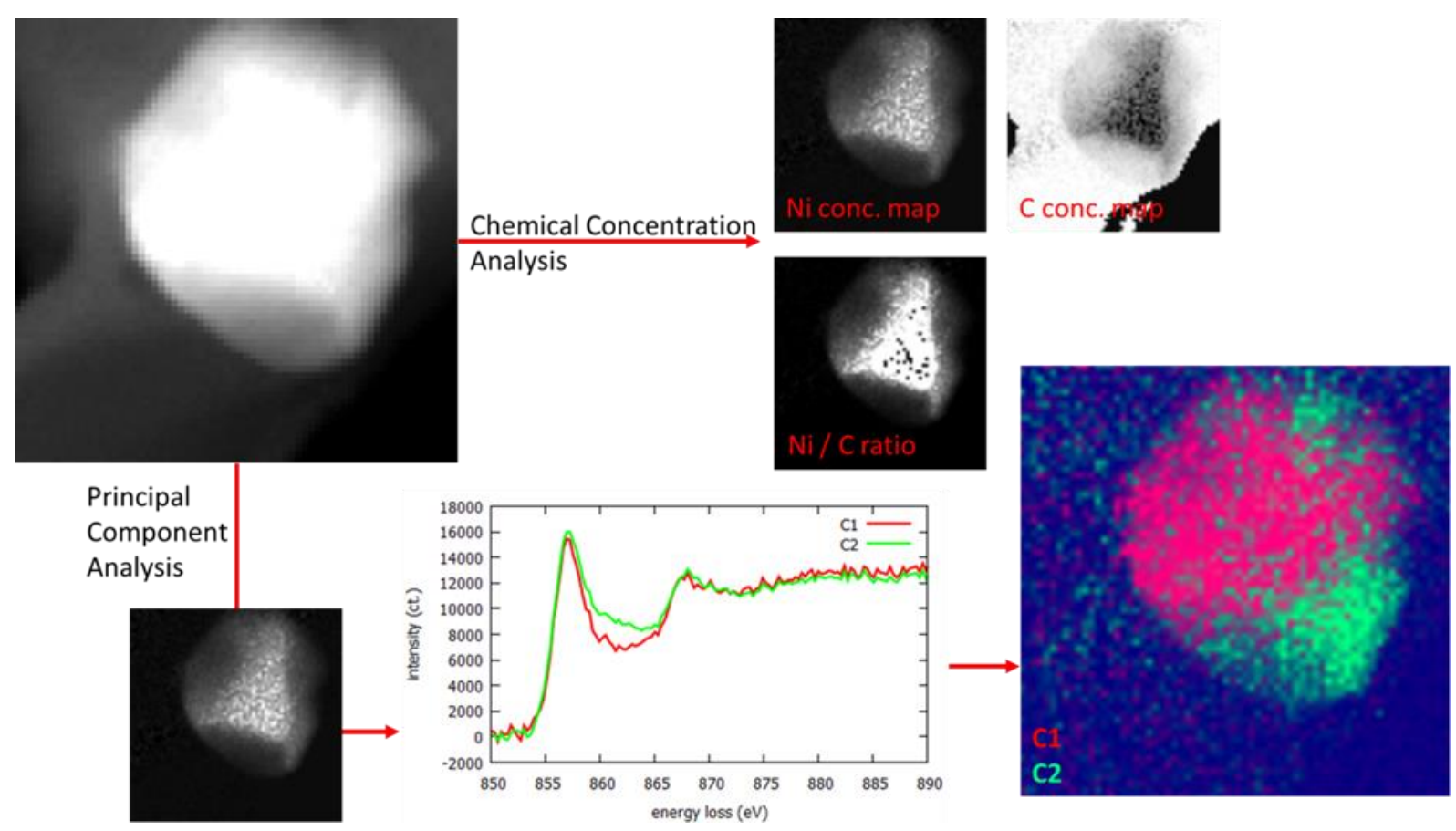

Figure 9: Chemical concentration and principal component analysis of a single Ni particle on YSZ after exposure to flowing $\mathrm{CO}\left(1 \mathrm{~mL} \mathrm{~s}^{-1}\right)$ at $1273 \mathrm{~K}$ for $1 \mathrm{~h}$. Upper left: HAADF image. Right upper corner: $\mathrm{C}$ and $\mathrm{Ni}$ concentration maps alongside $\mathrm{Ni} / \mathrm{C}$ ratio map. Lower panel: $\mathrm{Ni}$ L-edges for two chemically different Ni species (C1 and $\mathrm{C} 2)$ and distribution of these species within the Ni particle ( $\mathrm{C} 1$ red and $\mathrm{C} 2$ green). 